\title{
Fibras Reforçadas por Resina (FRC) em Ortodontia. Versatilidade Clínica - Parte 2
}

\author{
Daniel lanni Filho*, Lylian Tsai Strinta**, Yasushi Inoue Miyahira**, Eduardo Serpa**
}

\begin{abstract}
Resumo
As fibras de vidro e de polietileno podem ser utilizadas na prática ortodôntica em diversas situações clínicas, nos casos com ou sem extrações dentárias. Este artigo tem como objetivo mostrar algumas das aplicações clínicas nas quais as fibras contribuíram de forma significativa para a realização dos tratamentos ortodônticos, simplificando-os e aumentando a eficiência clínica. As fibras foram utilizadas principalmente em segmentos de ancoragem e na substituição da banda pela colagem da associação fibra/tubo nos molares.
\end{abstract}

Palavras-chave: Fibras de vidro. Filamentos cerâmicos. Fibras de polietileno. Ortodontia.

\section{INTRODUÇÃO}

A engenharia de materiais tem desenvolvido pesquisas com o objetivo de aprimorar estruturas resistentes e, com os recentes avanços tecnológicos, passamos a utilizar as fibras de vidro na Ortodontia de modo inovador. Segundo Freudenthaler, Tischler e Burstone $\mathrm{A}^{4}$, as fibras proporcionam versáteis aplicações clínicas. Inicialmente, as fibras foram empregadas com o objetivo de promover contenção temporária de um ou mais elementos dentários, como nos casos de tratamentos periodontais, devido à necessidade da contenção de dentes com mobilidade em grau avançado, ou ainda nos tratamentos reabilitadores, com o objetivo de se confeccionar próteses fixas adesivas ou próteses fixas provisórias $^{2}$. Iniciamos agora uma nova fase também na especialidade ortodôntica, com a utilização de fibras de vidro e de polietileno, modificando, em parte, conceitos tradicionais na utilização da aparatologia fixa ${ }^{1,3,7}$. O que já é uma realidade nos EUA passa agora a ser também uma realidade no Brasil.

Uma importante aplicação clínica é a substituição das bandas pela colagem da associação fibra/tubo nos molares, com inúmeras vantagens, pois não é preciso separar dentes nem confeccionar e cimentar as bandas, o que diminui os problemas periodontais e a formação de manchas brancas.

Segundo Burstone ${ }^{1}$, as fibras são elementos que podem ser utilizados para unir um grupo de dentes que atuarão tanto como unidade ativa (movimentados), como reativa (ancoragem), sugerindo que determinados tratamentos ortodônticos podem ser realizados utilizando-se um menor número de braquetes e fios.

O número de braquetes pode ser diminuído em várias situações clínicas, como: a) quando as fases de alinhamento e nivelamento não são necessárias num primeiro momento, em virtude de uma boa

Mestre em Ortodontia pela Faculdade de Odontologia de Araraquara - UNESP. Coordenador do Centro de Cursos e Pesquisas Odontológicas Alpha Smile Campinas/SP.

** Alunos do Curso de Aperfeiçoamento em Ortodontia - nível avançado para experientes e especialistas do Alpha Smile Centro de Cursos e Pesquisa Odontológicas - Campinas/SP. 


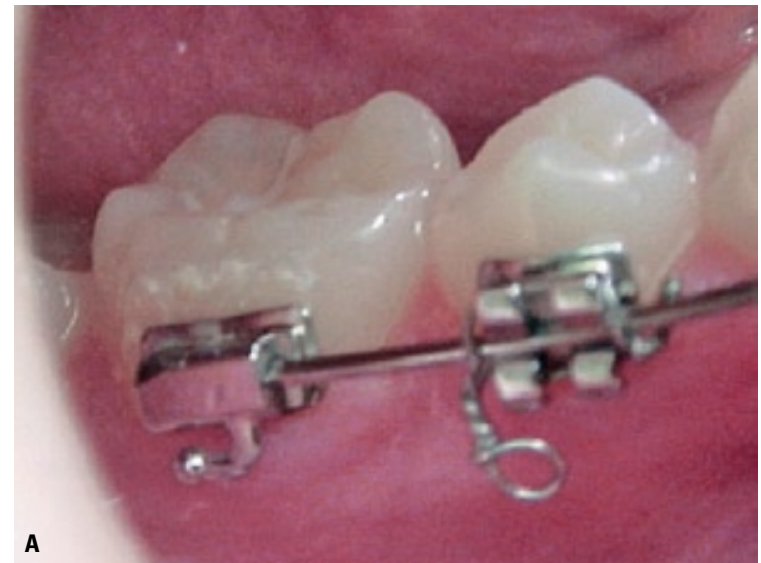

FIGURA $1 \mathrm{~A}$ - Tubo lingual associado à fibra de vidro.

oclusão e um bom posicionamento inicial dos dentes; b) quando o problema é inter-segmentar ou ainda, c) quando o problema (por exemplo, apinhamento) está localizado em um segmento específico do arco. Nesses casos, os segmentos sem grandes apinhamentos são unidos através da colagem de fibras, funcionando a partir desta união como um dente multirradicular reforçado ${ }^{4}$. Em cada segmento, um ou mais acessórios podem ser colados. Desse modo, é realizada grande parte do tratamento ortodôntico, como a correção da mordida aberta, a correção da mordida profunda ou ainda o fechamento dos espaços das extrações dentárias. Os braquetes são colados de modo tradicional, ou seja, em todos os dentes, somente na fase de realinhamento e renivelamento. Nesse caso, o paciente utilizou um número menor de braquetes durante a metade do tempo de tratamento, diminuindo o desconforto, melhorando a higienização e a estética.

Em outras situações, o paciente pode utilizar menos braquetes durante todo o tratamento, como nos casos em que os dentes posteriores encontram-se bem posicionados no início do tratamento. Quando os dentes apresentam problemas intra-arcos, como apinhamentos e giroversões de modo generalizado, o ideal é realizar o tratamento de modo tradicional, ou seja, a colagem dos acessórios em todos os dentes desde o início do tratamento. Nesse caso, as fibras podem ser associadas

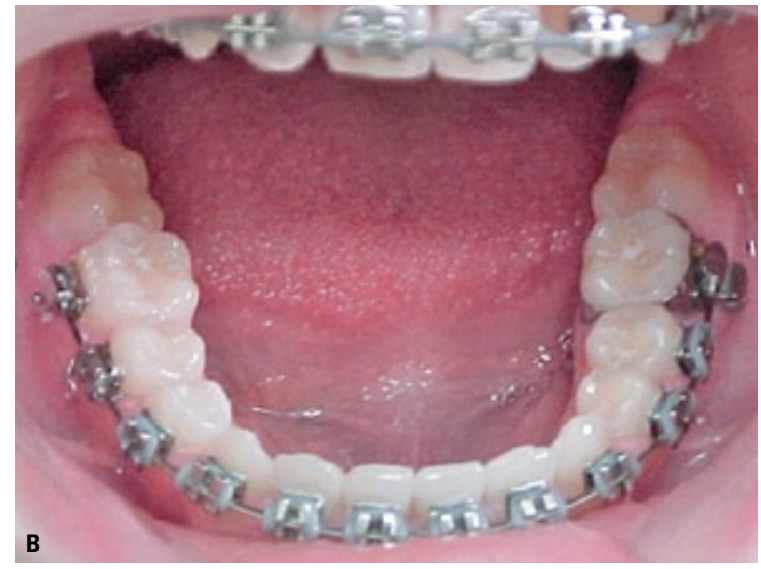

FIGURA 1B - Lado direito inferior - dente 46 com associação fibra-tubo e lado esquerdo inferior dente 36 com banda.

aos tubos na colagem destes aos molares, em substituição às bandas (Fig. 1A, B).

Apresentaremos dois casos clínicos para ilustrar estas aplicações clínicas

\section{Caso clínico 1 \\ Classe I de Angle com apinhamento}

O paciente J.P.A.N, gênero masculino, 22 anos, apresentava na análise facial ligeira retrusão do mento, perfil convexo (Fig. 2A, B). Entretanto, apresentava relação dentária de Classe I de Angle, com apinhamento ântero-superior e inferior e os caninos mal relacionados no plano vertical (Fig. 3A, B, C).

Tendo em vista que os segmentos posteriores encontravam-se naturalmente bem relacionados nos três planos do espaço (relação ântero-posterior Classe I de Angle; relação vertical com boa intercuspidação e relação transversal com ausência de mordida cruzada posterior), optou-se pela consolidação destes segmentos, utilizando-se fibra de polietileno da marca Connect (Ribbond).

Tradicionalmente, essa consolidação seria feita com a utilização de bandas e braquetes e um segmento de fio rígido. Entretanto, o que se observa muitas vezes nesta situação é que, em função da espessura das bases dos braquetes e dos torques previamente incorporados nesses acessórios, alteram-se as relações dentárias inicialmente consideradas ótimas. Assim, o ortodontista tem que adicionar torções 


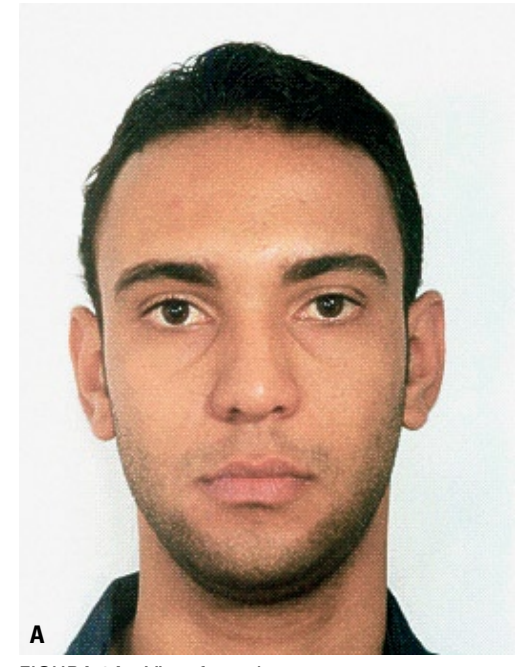

FIGURA 2A - Vista frontal.

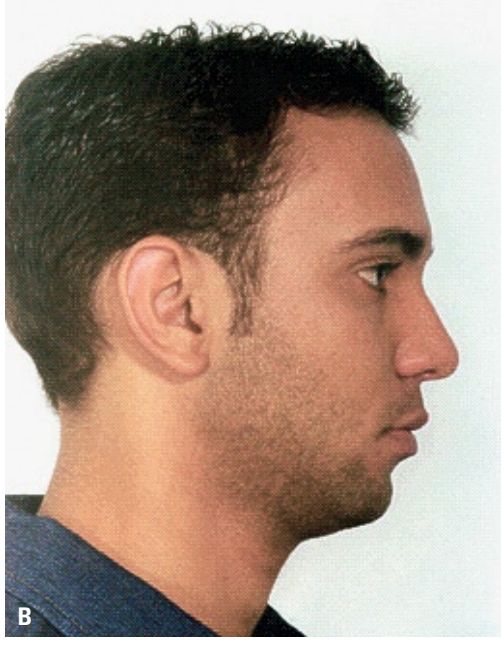

FIGURA 2B - Vista lateral.

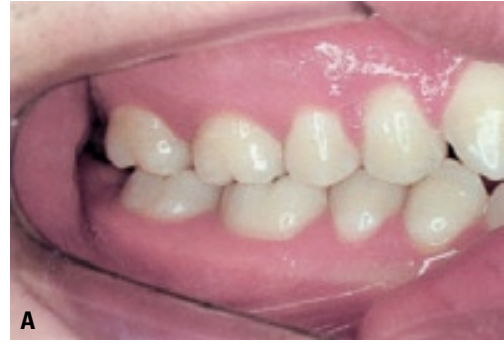

FIGURA 3A - Foto lateral direita com dentes posteriores bem relacionados.

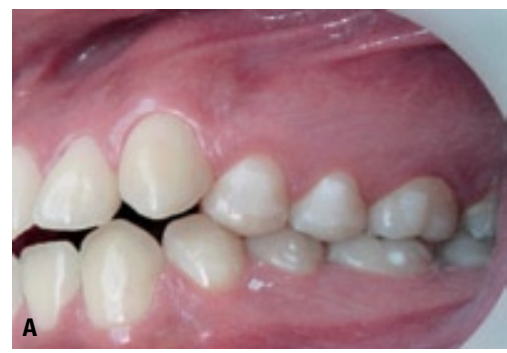

FIGURA 4A - Dentes posteriores condicionados com ácido fosfórico $37 \%$.

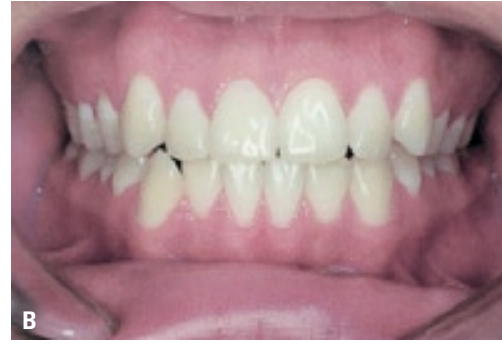

FIGURA 3B - Foto frontal. Os caninos estão ma relacionados no plano vertical.

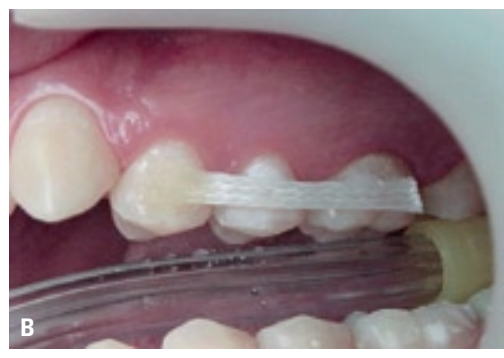

FIGURA 4B - Fibra adaptada à superfície vestibu lar previamente impregnada pela resina Flow. (Kit Connect).

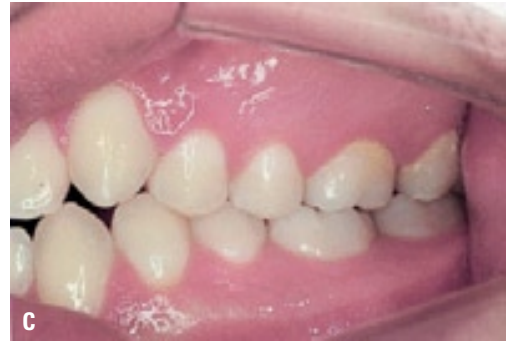

FIGURA 3C - Foto lateral esquerda com dentes posteriores bem relacionados e o canino em infra-oclusão.

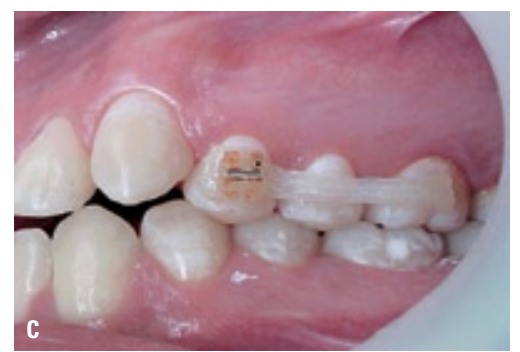

FIGURA 4C - Colagem de braquete estético Spirit (Ormco), sobre a fibra. nos fios (torque), realizar dobras verticais, etc., com o intuito de posicionar os dentes a fim de se obter o mesmo padrão de relacionamento dentário que o paciente apresentava naturalmente no início do tratamento. Com a colagem da fibra, objetiva-se manter o relacionamento dentário considerado satisfatório, diminuir o trabalho do ortodontista, facilitar a prática clínica, diminuir o uso de acessórios, minimizar o efeito de recidiva (mantendo os dentes em suas posições originais), diminuir os custos com a aparatologia e aumentar a eficiência clínica.

Para a colagem das fibras, as superfícies vestibulares dos dentes posteriores foram condicionadas com ácido fosfórico a 37\%, lavadas e secas, com o isolamento relativo.

Foi aplicada à superfície condicionada, a resina 'Flow' do Kit Connect. Do mesmo modo, a fibra em forma de fita, com largura de $2 \mathrm{~mm}$, foi tam- 

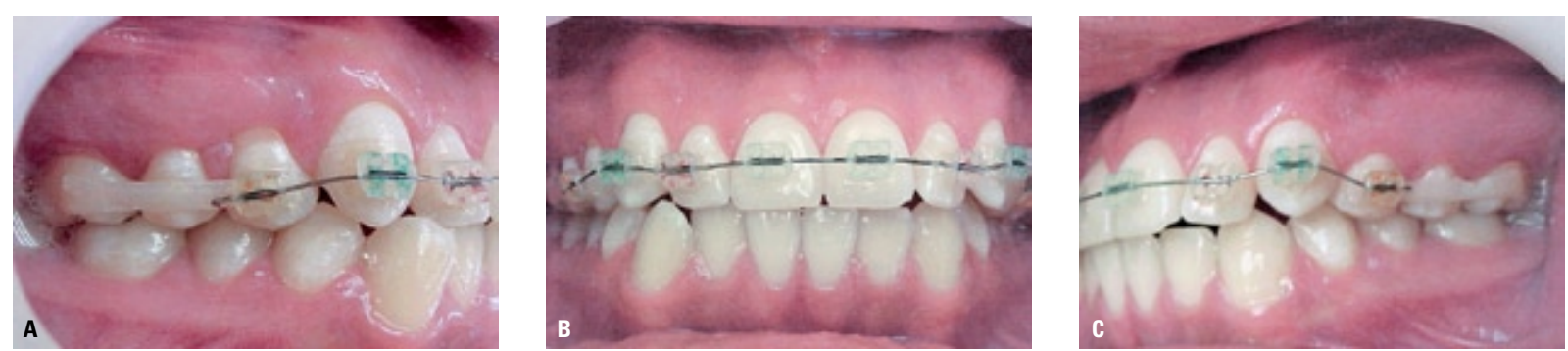

FIGURA 5A, B, C - Dentes posteriores unidos pela Fibra de vidro Connect atuando como unidade de ancoragem e dentes anteriores com braquetes de forma tradicional utilizando o Sistema Ortho Solo (ORMCO).
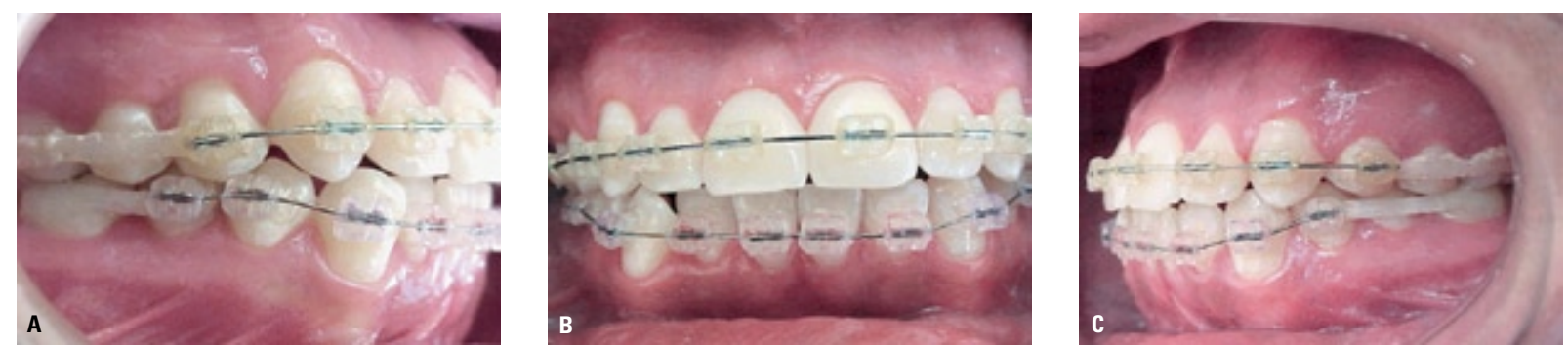

FIGURA 6A, B, C - Após um mês, foi feita a colagem das fibras e braquetes nos segmentos posteriores inferiores. Observa-se também uma melhora na posição nos dentes superiores anteriores utilizando-se o fio Copper Ni-Ti 0,016.

bém impregnada pela mesma resina. Posteriormente, a fita foi acomodada à superfície vestibular dos dentes posteriores, procedendo-se a polimerização por 30 segundos (Fig. 4A,B,C).

Sobre a fita pré-polimerizada foi colado um braquete estético Spirit (Ormco), aplicando-se na base do braquete uma fina camada da mesma resina 'Flow' e uma pequena porção de resina para restauração, com carga, da marca 3M, seguindo-se a polimerização por mais 60 segundos. Esse procedimento foi realizado em ambos os lados, unindo os segmentos posteriores.

Nos elementos anteriores, que se apresentavam apinhados, foram colados de modo tradicional os braquetes estéticos, utilizando o Sistema Ortho Solo (Ormco) (Fig. 5A,B,C). Assim, tínhamos os dentes apinhados com braquetes e os segmentos bem relacionados unidos por uma barra de fibra, sobre a qual foi colado somente um único braquete. Os segmentos posteriores foram utilizados como unidades de ancoragem, utilizando somente um braquete em cada segmento posterior, o que está de acordo com Burstone e Kuhlberg ${ }^{1}$ e condiz com o intuito de diminuir o número de acessórios utilizados. Para diminuir a quantidade de fios no ali- nhamento, optou-se pela utilização do fio Copper $\mathrm{Ni}$-Ti 0.016 que libera forças leves e contínuas e aumenta a velocidade do alinhamento dos dentes.

No mês seguinte, o mesmo procedimento foi realizado no arco inferior. Foram coladas fibras nos dentes posteriores e braquetes estéticos nos dentes anteriores apinhados. Com um mês de alinhamento superior já se observa a melhora substancial na posição dos incisivos superiores (Fig. 6A,B,C). Dois meses após, observa-se o alinhamento dos dentes superiores e inferiores quando o fio Copper Ni-Ti 0,016 foi substituído pelo Copper Ni-Ti 0,016 x 0,022, utilizando-se, dessa forma, somente dois fios para concluir a fase de alinhamento e nivelamento. Um terceiro e último fio de aço $0,018 \times 0,025$ foi utilizado para promover os torques e melhorar o posicionamento das raízes dentárias (Fig. 7A,B,C).

$\mathrm{Na}$ fase de finalização, as fibras do arco superior e inferior foram removidas. As fibras, devido à sua incapacidade de resistir a movimentos de torção, são fáceis de serem removidas e eventuais resíduos podem ser removidos com fresas multilaminadas (Fig.7D,E,F).

A relação de intercuspidação dos dentes poste- 

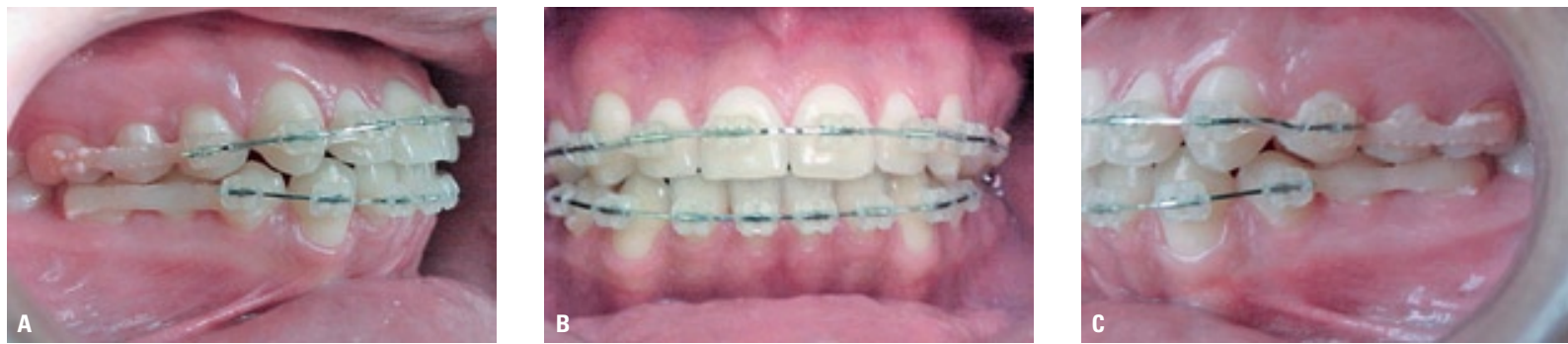

FIGURA 7A, B, C - Fio de aço 0,018 x 0,025 foi utilizado para promover os torques e melhorar o posicionamento das raízes dentárias.
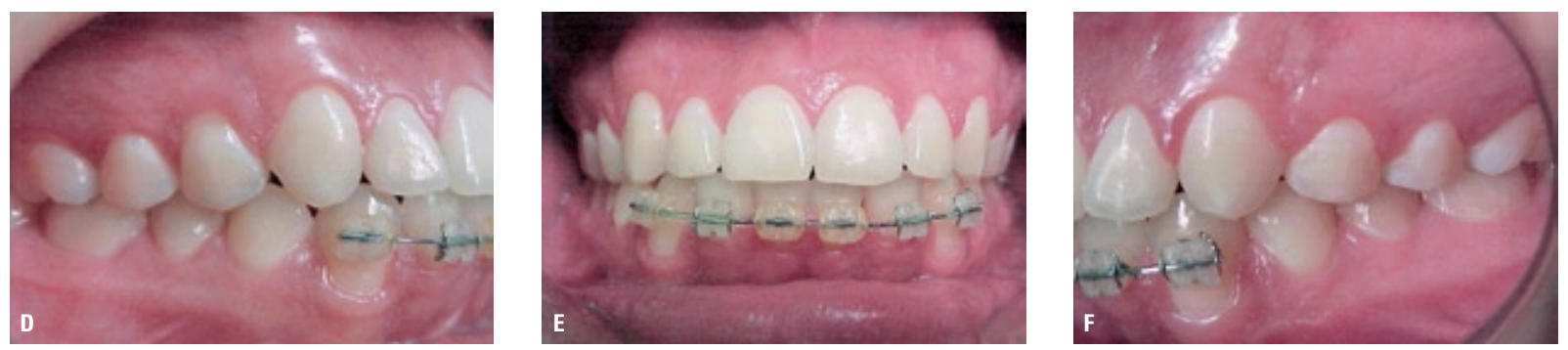

FIGURA 7D, E, F - Facilidade em remover as fibras devido à sua incapacidade de resistir a movimentos de torção.
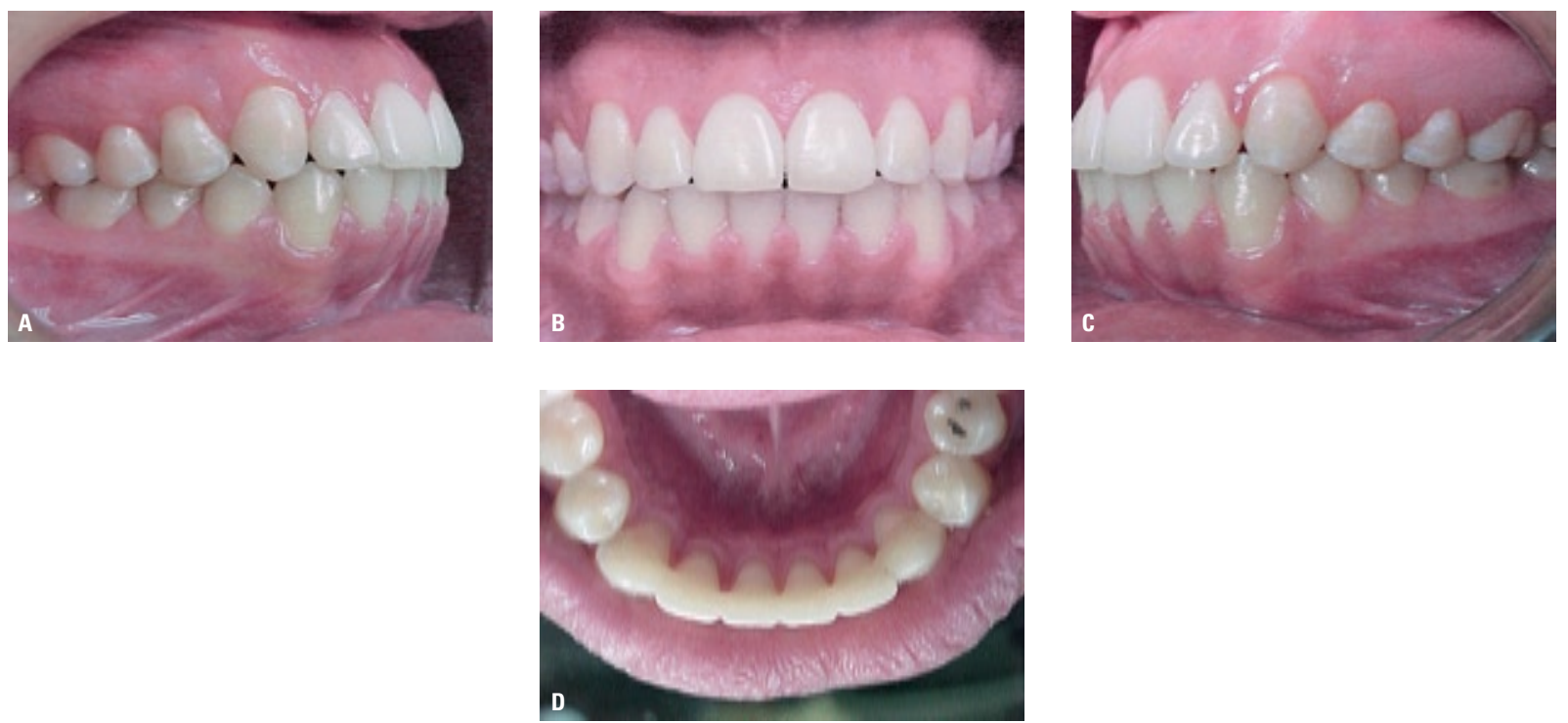

FIGURA 8A, B, C, D - A relação de intercuspidação dos dentes posteriores permaneceu inalterada durante todo o tratamento. Como contenção, no arco inferior, foi utilizada a fibra².

riores permaneceu inalterada durante todo o tratamento, como podemos observar na figura 8 .

A vantagem de unir dentes bem posicionados e em equilíbrio na boca é que estes podem ser utilizados como unidades de ancoragem, favorecendo e facilitando a movimentação de outros mal posicionados. Acredita-se que, pelo fato de estarem em equilíbrio na boca, aumenta-se a estabilidade dos resultados alcançados.

De acordo com Freilich, Karmaker, Burstone e Goldberg ${ }^{2}$, outra aplicabilidade da fibra seria a confecção de contenções fixas estéticas, em substituição à barra em fio de aço colada na face lingual dos dentes anteriores inferiores, que normalmente se utiliza para contenção ${ }^{2}$.

Clinicamente, no entanto, a fibra tem se mos- 
trado pouco resistente para essa aplicabilidade, não apresentando boa durabilidade quando se necessita que o paciente permaneça com a contenção por um período acima de um ano. Tais evidências tornam necessárias pesquisas mais aprofundadas sobre a durabilidade clínica da fibra nessas situações, a fim de que se possa estabelecer um padrão para a sua utilização na confecção de contenções estéticas ${ }^{6}$.

\section{Caso clínico 2}

\section{Classe I de Angle com apinhamento e exodontia de incisivo inferior}

O paciente L.F., leucoderma, 29 anos, gênero masculino, portador de má oclusão Classe I de Angle, apresentava apinhamento na região anterior dos arcos dentários superior e inferior, com discrepância de modelo inferior de 4,5 mm.

$\mathrm{Na}$ análise facial em norma frontal, o paciente apresentava simetria, aumento do terço inferior da face e selamento labial competente. Em norma lateral apresentava a mandíbula levemente retruída. (Fig. 9)

Considerando o ótimo relacionamento dos segmentos posteriores direito e esquerdo nos planos vertical, ântero-posterior e transversal, relação molar Classe I de Angle e boa intercuspidação dos pré-molares e caninos (Fig.10 A,B,C,D), inovou-se o planejamento e tratamento deste caso, utilizando-se fibras de vidro ao invés de bandas e braquetes, para unir e consolidar os segmentos posteriores que não se pretendia alterar durante o tratamento, em virtude do ótimo relacionamento oclusal, do equilíbrio e da estabilidade (Fig. 11 A,B,C).

Para se obter espaço e alinhar os dentes apinhados, optou-se pelos desgastes interproximais nos dentes ântero-superiores e a exodontia do dente 41, no arco inferior (Fig.12B).

Para unir os dentes posteriores superiores foram coladas fibras de vidro da marca Superfiber Orthodontic (Superfiber) bilateralmente de canino a segundo pré-molar, e braquetes estéticos Spirit (Ormco) foram colados de canino a canino, no segmento ântero-superior. Os braquetes dos caninos foram colados sobre a fibra. Pretendia-se que o grupo de dentes unidos pela fibra atuasse como unidade de ancoragem e, portanto, não fosse movimentado. Assim, os braquetes dos caninos serviram como ponto estável para a movimentação dos incisivos. Iniciou-se o alinhamento no arco superior com fio Copper Ni-Ti 0,016 (Ormco).

No arco inferior foram coladas fibras de vidro da marca Fibrekor (Jeneric/Pentron) bilateralmente de primeiros molares até os caninos (Fig. 12A,B,C). Essa fibra se diferencia das demais por ser pré-im-

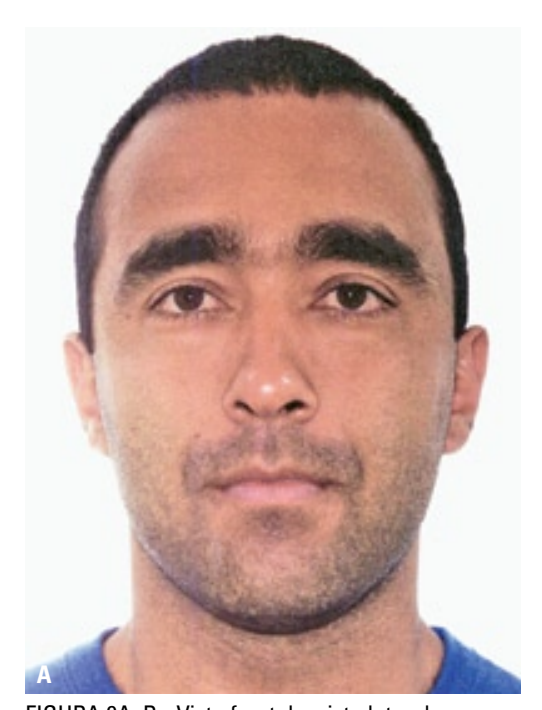

FIGURA 9A, B - Vista frontal e vista lateral.

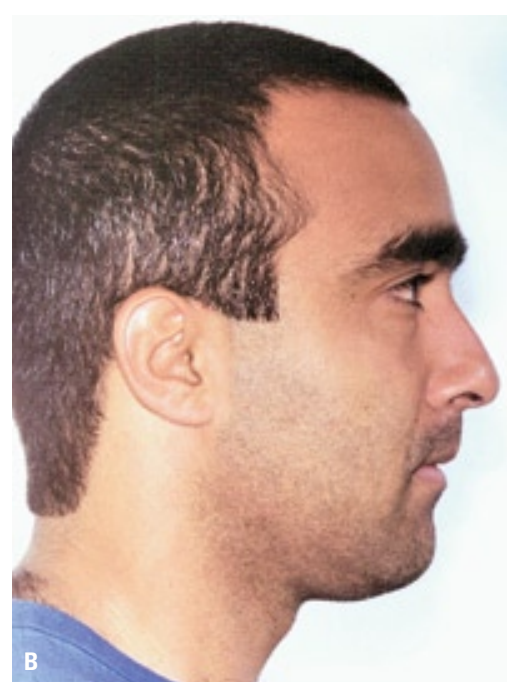



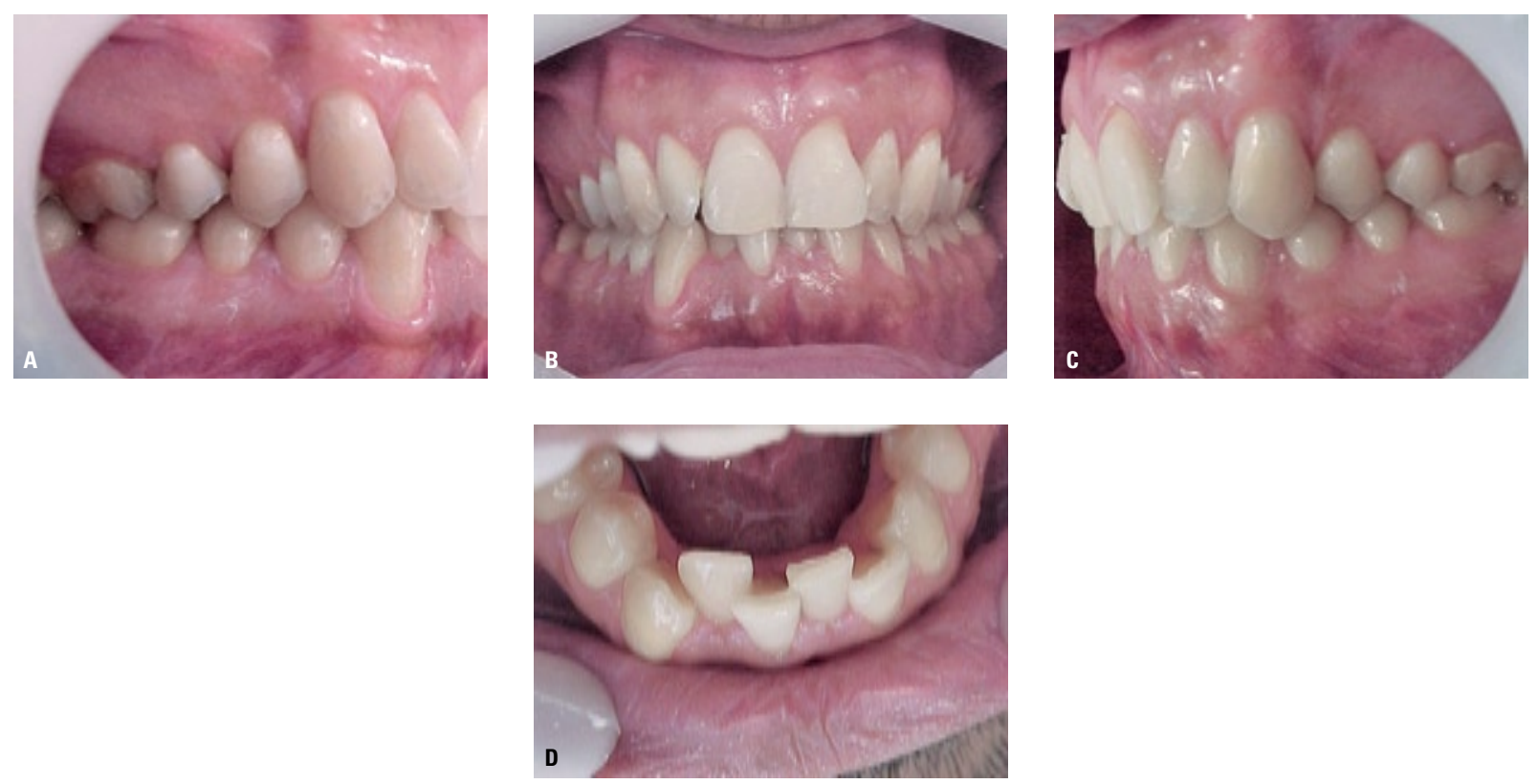

FIGURA 10 - A) Vista lateral direita, dentes posteriores bem relacionados. B) Vista frontal, apinhamento anterior superior e inferior. C) Vista lateral esquerda, dentes posteriores bem relacionados. D) Vista oclusal, apinhamento anterior inferior.
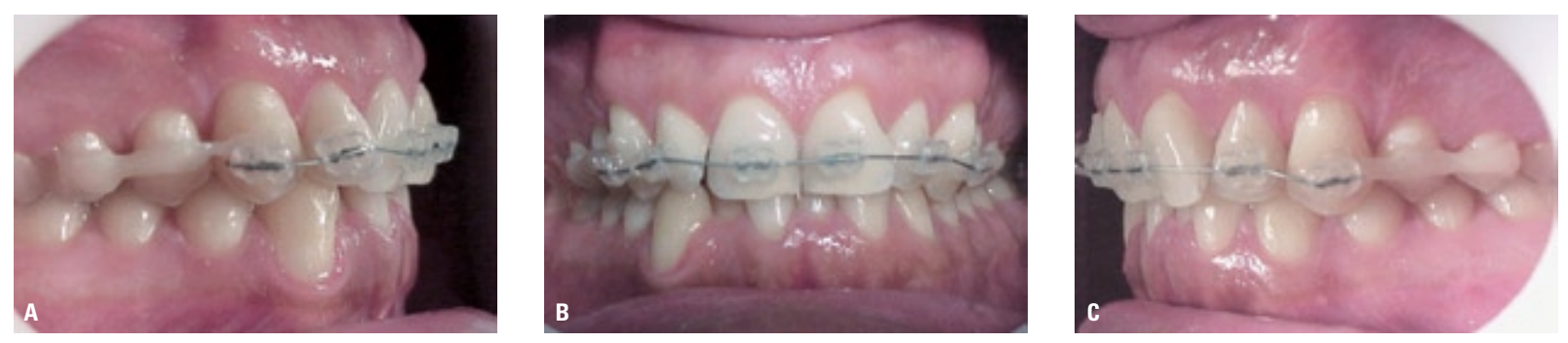

FIGURA 11 - A) Vista lateral direita. Colagem da fibra Connect de segundo pré-molar a canino e colagem tradicional de um braquete no canino. B) Vista frontal. Colagem de braquetes estéticos Spirit (Ormco) nos incisivos com apinhamento. C) Vista lateral esquerda. Colagem da fibra Superfiber Orthodontic (Superfiber) de segundo pré-molar a canino e colagem tradicional de um braquete no canino. Alinhamento inicial com o fio Copper Ni-Ti 0,016 de canino a canino.
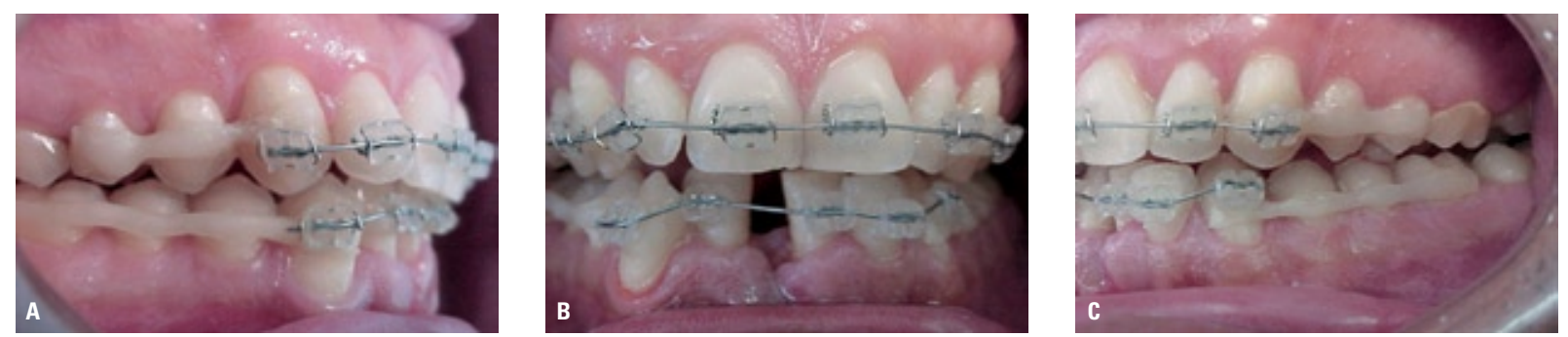

FIGURA 12A, B, C - No arco inferior foi feita colagem da fibra Fibrekor (Jeneric/Pentron) do primeiro molar ao canino. Braquetes estéticos Spirit (Ormco) foram colados de canino a canino e o levante de mordida com 'stops' de resina composta na face oclusal dos dentes 14 e 24 permitiu o início do alinhamento com fio Copper Ni-Ti 0,016 .

pregnada por resina cuja desvantagem é seu tempo de vencimento, em função da resina ${ }^{3}$. Braquetes estéticos Spirit (Ormco) foram utilizados no segmento anterior inferior, iniciando o alinhamento com arco de Copper Ni-Ti 0,016 (Ormco).
Os procedimentos de colagem foram feitos segundo as normas do fabricante, ou seja, ataque ácido, lavagem, secagem e aplicação do adesivo de colagem. Como reforço foi colocada uma camada de resina composta sobre a fibra de vidro, com o 

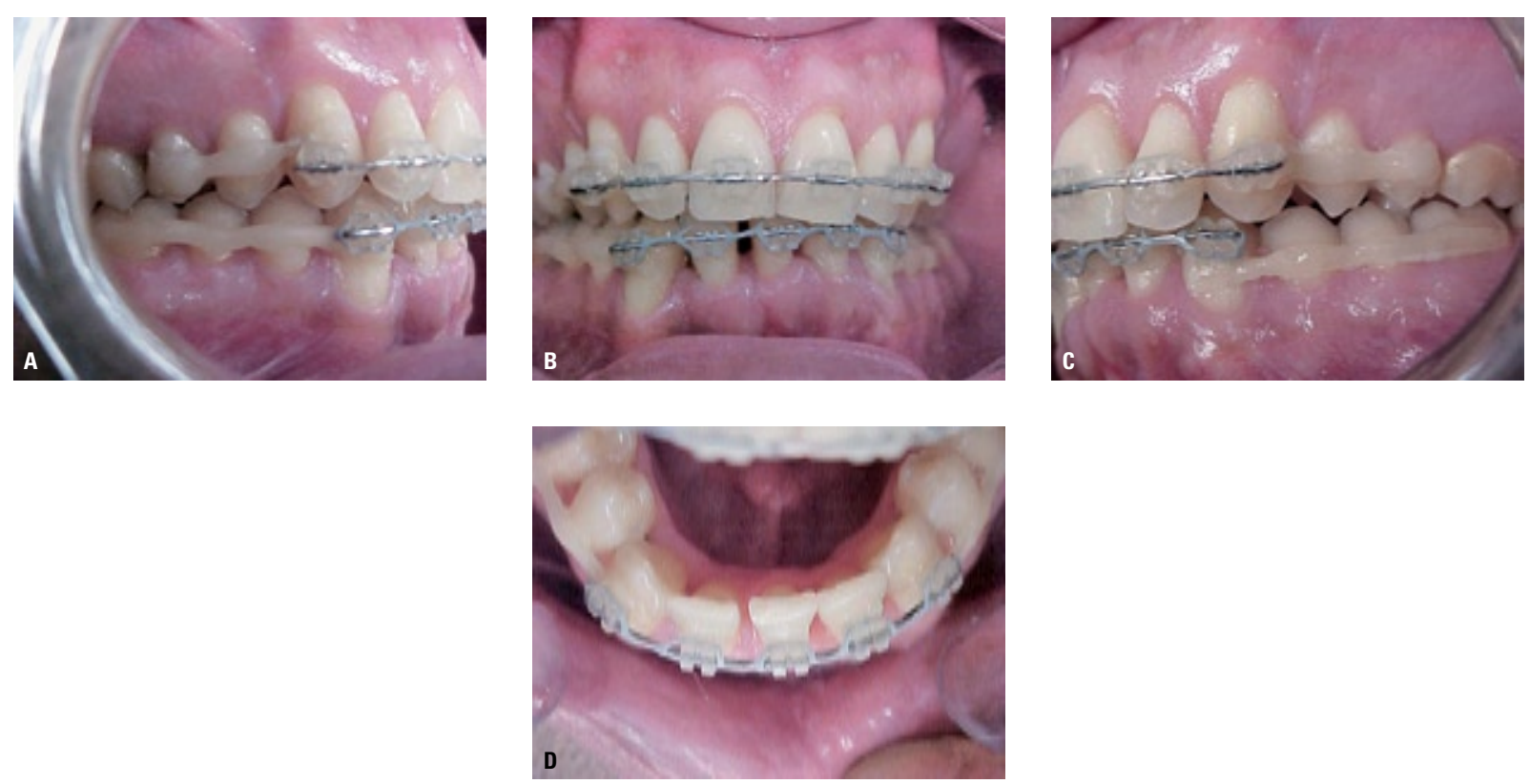

FIGURA 13 - A, C) Pode-se observar o bom relacionamento do segmento posterior sem perda de ancoragem. B) Fechamento de espaços com elástico em cadeia na mecânica de deslizamento utilizando-se 0 arco de aço 0,019 x 0,025 como guia. D) Vista oclusal dos incisivos inferiores em fase de finalização.
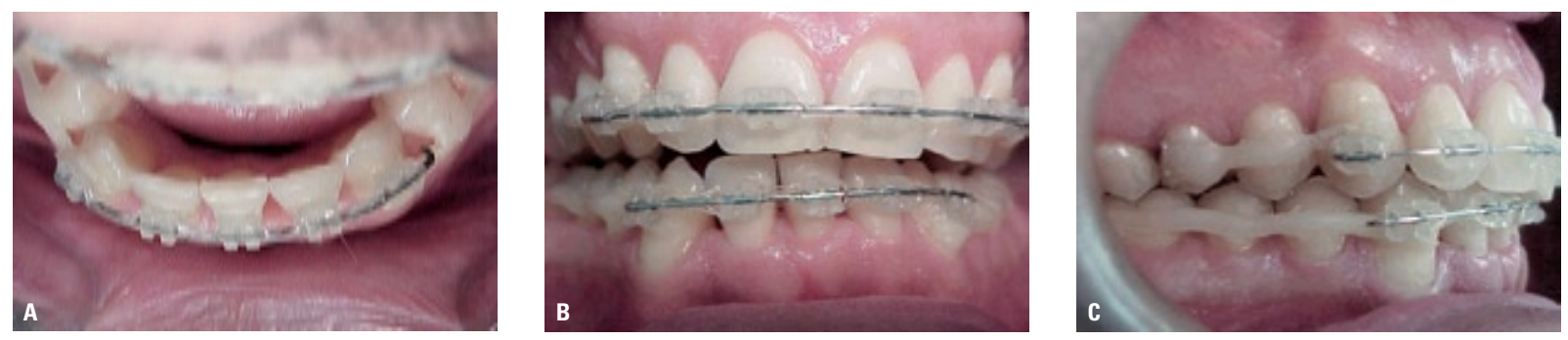

FIGURA 14A, B, C - Vista oclusal, frontal e lateral direita em fase de finalização.

objetivo de aumentar a sua resistência e longevidade, tendo em vista que nesse caso a fibra está protegida dos fluidos bucais.

$\mathrm{Na}$ figura 13 pode-se observar um bom alinhamento e nivelamento do dentes superiores. $\mathrm{O}$ espaço da exodontia do dente 41 foi fechado utilizando-se elástico em cadeia, com mecânica de deslizamento num arco de aço 0,019 x 0,025.

Uma das vantagens da utilização das fibras em Ortodontia é a diminuição do tempo clínico, pois não requer a separação dos dentes, o preparo das bandas e nem a bandagem propriamente dita. Obviamente, em algumas situações, como, por exemplo, no uso do AEB, a bandagem é imprescindivel, mas em muitas outras situações nas quais as bandas eram tradicionalmente confeccionadas, atualmente elas podem ser dispensadas. O tempo e os custos com acessórios também foram diminuídos em virtude da utilização de menos acessórios ortodônticos. Segundo Freilich et al. ${ }^{2}$, em virtude da utilização de fios termoativados e do menor número de dentes a serem movimentados, o alinhamento e nivelamento inicial foi mais rápido, diminuindo o tempo total do tratamento, aumentando o conforto durante o tratamento e melhorando a higienização e a estética da aparatologia fixa (Fig. 14 A,B,C). 


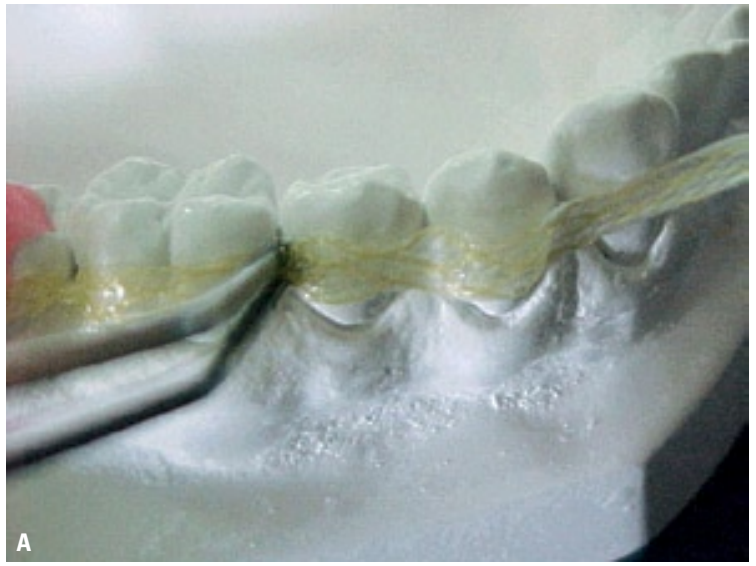

FIGURA 15A - Adaptação da fibra no modelo com auxílio de uma pinça clínica.

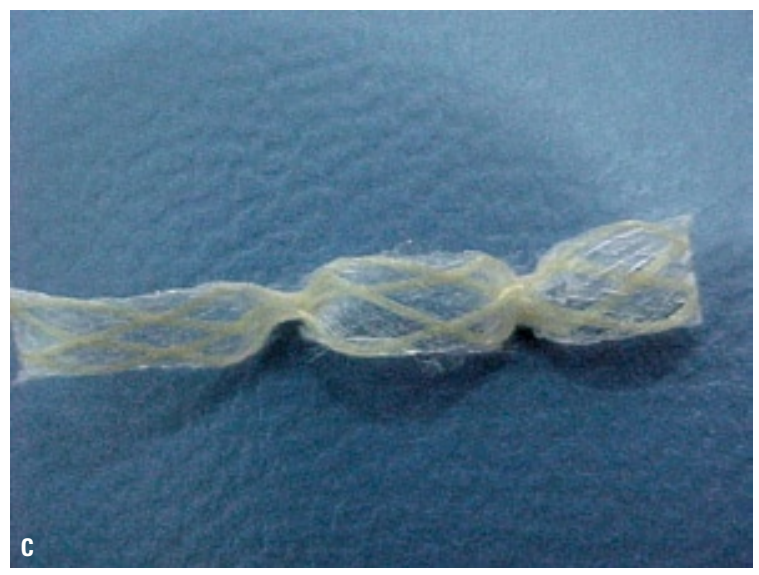

FIGURA 15C - Foto da estrutura de fibra pré-moldada.

\section{Técnica de colagem da fibra}

As fibras podem ser coladas ao dente de duas formas: pela técnica direta ou pela técnica indireta.

- Técnica direta: 1) condicionamento ácido; 2) aplicação do adesivo e polimerização por 15 segundos; 3) aplicação da resina no dente; 4) aplicação do adesivo na fibra (adaptando-a nos dentes) e fotopolimerização por 15 seg; 5) aplicação da resina no braquete, posicionando-o no dente já com a fibra pré-polimerizada; 6) polimerização de todo o conjunto. A desvantagem consiste na dificuldade de se adaptar a fibra no dente em locais de difícil acesso, como distal de primeiros e segundos molares.

- Técnica indireta: com a finalidade de facilitar os passos clínicos da adaptação da fibra no den-

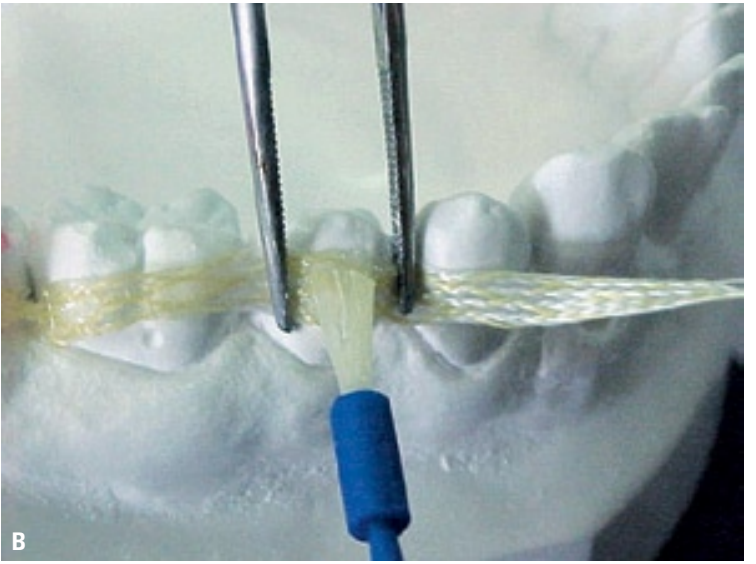

FIGURA 15B - Aplicação do adesivo na fibra e polimerização por 15 seg.

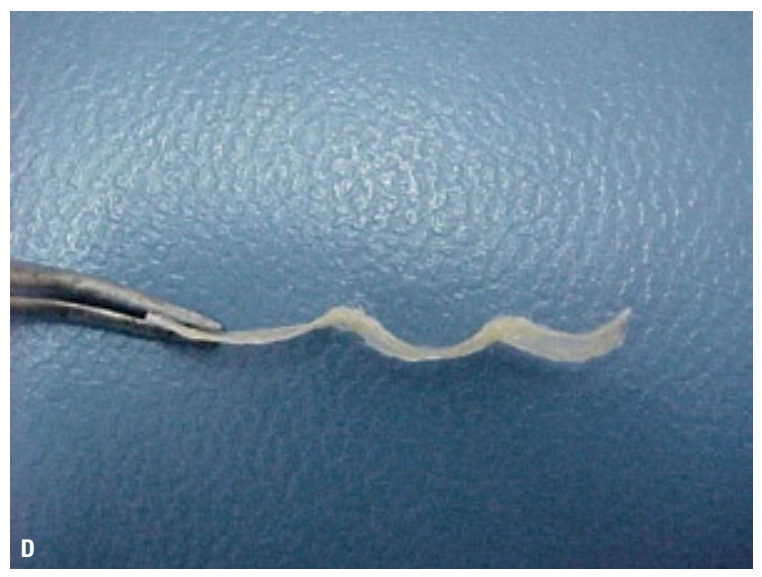

FIGURA 15D - Foto oclusal da estrutura pré-moldada.

te, os autores desse trabalho desenvolveram um modo alternativo que consiste em adaptar a fibra ao modelo de estudo, procedendo a pré-polimerização (Fig. 15 A,B,C,D).

Após o preparo do dente (condicionamento ácido e aplicação do adesivo) uma camada de resina é colocada no dente e a estrutura de fibra pré-moldada é posicionada, com posterior polimerização. A principal vantagem é o ganho do tempo clínico.

Há diferentes tipos de fibras com aplicação em Ortodontia, como relatado por Ianni Filho ${ }^{6}$. Nesses casos clínicos foram utilizados 3 tipos: fibra de polietileno Connect, fibra de vidro Fibrekor e fibra de vidro modificada SuperfiberOrtodôntica (Fig. 16). 


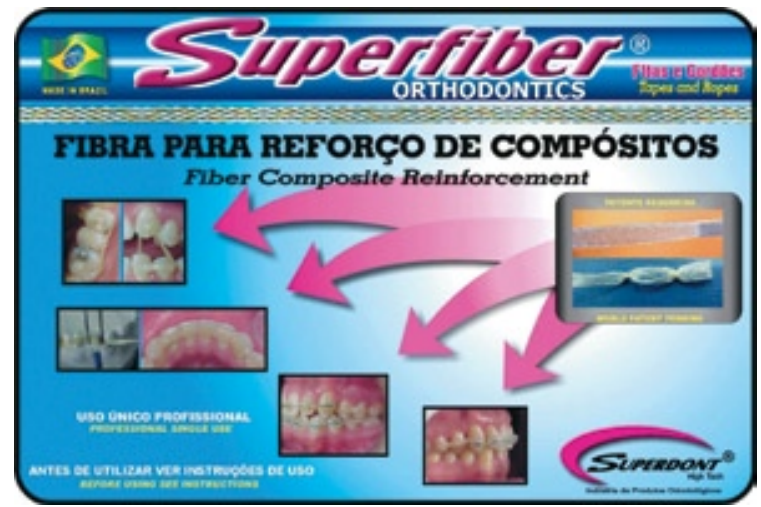

FIGURA 16 - Kit Superfiber Ortodôntica - fibra de vidro modificada.

\section{CONCLUSÃO}

As fibras despontam como um excelente recurso para o auxílio na correção ortodôntica, em diversas situações clínicas.Tendo em vista a grande quantidade de pacientes adultos que procuram o ortodontista por motivos estéticos e a possibilidade de diminuir a recidiva e a diminuição do tempo de tratamento, as fibras de vidro, de polietileno e de vidro modificada são uma excelente opção ${ }^{5}$. Tratase de uma abordagem segura, previsivel e que certamente diferencia o profissional que a utiliza, com vistas à eficiência e satisfação do paciente.

\title{
Fiber Reinforced Composite (FRC) in Orthodontic. Clinical Versatility - Part II
}

\begin{abstract}
Glass and polyethylene fibers can be used in orthodontic practice on several clinical(s) situations, in cases with or without teeth extraction. The objective of this article is to show some of the clinical applications in which the fibers contributed in a positive way to improve the performance of orthodontic treatments, simplifying and raiseing the clinical efficiency. These fibers were mainly used on anchorage segments, and as a substitute for the band by bonding the fiber/tube association in molars.
\end{abstract}

Key words: Fiberglass. Ceramic filaments. Polyethylene fiber. Orthodontic.

\section{REFERÊNCIAS}

1. BURSTONE, C. J.; KUHLBERG, A. J. Fiber-reinforced composites in orthodontics. J Clin Orthod, Boulder, v. 34, p. 271-279, 2000.

2. FREILICH, M. A.; KARMAKER, A. C.; BURSTONE, C. J.; GOLDBERG, A. J. Development and clinical application of a lightpolymerized fiber-reinforced composite. J Prosthet Dent, St. Louis, v. 80, p. 311-318, 1998.

3. FREILICH, M. A.; MEIRES, J. C.; DUNCAN, J. P.;GOLDBERG, A. $J$. Fiber-reinforced composites in clinical dentistry. Chicago: Quintenssence, 1999.

4. FREUDENTHALER, J. W.; TISCHLER, G. K.; BURSTONE, C. J. Bond strenght of fiber-reinforced composite bars for orthodontics attachment. Am J Orthod Dentofacial Orthop, St. Louis, v. 120, p. 648-653, 2001.

5. GOLDBERG, A. J.; BURSTONE, C. J. The use of continuous fiber reinforcement in dentistry. Dent Mater, Copenhagen, v. 8, p. 197-202, 1992.

6. IANNI FILHO, D.; STRINTA, L. T.; NIZZOLA, C. E. C. Uso de fibras de vidro e polietileno reforçadas por resina em Ortodontia
- Parte I. R Dental Press Ortodon Ortop Facial, Maringá, v. 8, n. 4, p. 51-57, jul./ago. 2003.

7. KARAMAN, A. I.; KIR, N.; BELLI, S. Four applications of reinforced polyethylene fiber material in orthodontic practice. Am J Orthod Dentofacial Orthop, St. Louis, v. 121, p. 650-654, 2002.

8. KARMAKER, A. C. et al. Performance of fiber-reinforced composites intended for prosthodontic frameworks. ANNUAL MEETING OF SOC BIOMATERIALS, 23., 1997, New Orleans. Proceedings... New Orleans: Society of Biomaterials, 1997. p. 231.

\section{Endereço para correspondência}

Daniel lanni Filho

Rua Embiruçu, 250 Alphaville

Alpha Smile Centro de Cursos e Pesquisas

CEP 13098-320 - Campinas - SP

E-mail: recadodaniel@terra.com.br 